\title{
FRACTURE MECHANICS AND BEAM THEORY ANALYSES OF SEMI-ELLIPTICAL CRACKS ORIGINATING IN THE BASE OF RAIL
}

\author{
David Y. Jeong \\ Michael E. Carolan \\ Hailing Yu \\ Benjamin Perlman \\ Volpe National Transportation Systems Center \\ Research and Innovative Technology Administration \\ US Department of Transportation \\ Cambridge, Massachusetts, USA \\ Jeffrey E. Gordon \\ Federal Railroad Administration \\ US Department of Transportation \\ Cambridge, Massachusetts, USA
}

\begin{abstract}
In May 2011, a derailment of a passenger train occurred in a tunnel in the northeast region of the United States. Fortunately, no serious injuries or fatalities resulted from this derailment. The probable cause of the derailment was determined to be a broken rail from a defect originating in the base of the rail. This internal rail base defect is characterized as having a crescent, thumbnail, or semi-elliptical shape. In addition, the formation and growth of this defect may have been exacerbated by corrosion.

This paper describes engineering calculations to estimate the growth rate of this type of rail base defect. These engineering calculations are based on applying the principles of fracture mechanics and beam theory. Fracture mechanics principles are applied to determine stress intensity factors for the semi-elliptical shaped defect with different aspect ratios. Stress intensity factors are then used to estimate the growth of the defect under the accumulation of tonnage from repeated wheel passages. For this purpose, the rail is assumed to behave as a beam in bending.
\end{abstract}

\section{INTRODUCTION}

The Federal Railroad Administration (FRA) Office of Research and Development sponsors research to evaluate and improve the effectiveness of rail manufacturing, inspection, and maintenance and repair programs on reducing rail failures under service conditions and increasing rail service life. For several decades, the Volpe National Transportation Systems Center (Volpe Center) has provided technical support to the FRA by managing and conducting research [1]. Moreover, the Volpe Center applies the basic principles of solid mechanics, metal fatigue, and fracture mechanics to develop analysis tools and to conduct engineering studies to evaluate rail structural integrity.

Past FRA/Volpe Center rail integrity research has focused on investigations of a particular type of rail defect called the detail fracture [2]. Particular attention has been given to this internal rail head defect because data on detected defects suggests that detail fractures account for about 75 percent of the rail defect population in continuous welded rail (CWR) track in North America.

However, the probable cause of a May 2011 derailment of a passenger train in a tunnel in the northeast region of the United States was a broken rail from a defect that originated in the underside of the rail base rather than the head. Figure 1 shows a photograph of the broken rail involved in this derailment. With increased traffic accumulation and repeated bending of the rail, the defect propagated transversely upward through the web of the rail. As the defect progressed into the head/web area, it turned longitudinally beneath the rail head before a portion of the rail head dislodged. 
The photograph in Figure 2 shows that the rail base defect has a crescent, thumbnail, or semi-elliptical shape. The defect appears to radiate from a corrosion pit, which acted as a stress riser. Moreover, the corrosion pit is suspected as the origin of the defect that eventually led to rail failure.

The photograph in Figure 3 shows rust on the underside of the rail base. The combination of the wet environment in the tunnel and electric traction current return in the rail appears to have exacerbated the formation and growth of this rail base defect. However, the effect of corrosion on the defect growth rate is not examined in this paper.

This paper describes fracture mechanics and beam theory analyses to estimate the growth of a semi-elliptical defect in the rail base due to repeated wheel passages, i.e. metal fatigue. In these analyses, the rail base defect is assumed to have already been formed with an initial, barely detectable size and aspect ratio for the semi-elliptical shape. Calculations are then performed to estimate the tonnage to grow the defect incrementally.

The estimation of defect growth is conducted in two steps. The first step is the calculation of stress intensity factors for the rail base defect, which is assumed to have a semi-elliptical shape. Two methods are applied to calculate stress intensity factors. The first method uses a closed-form solution from strength-of-materials (SOM) considerations based on seminal work by Gao and Herrmann [3]. This method was applied in previous work to calculate stress intensity factors of cracked Ibeams [4]. The second method is the application of finite element analysis to calculate stress intensity factors numerically. Moreover, finite element analysis provides a means to verify or confirm the results of the SOM method. The second step in the defect growth estimation is to apply the defect growth rate equation, which was used in previous research on detail fractures, to calculate the relative size of the semi-elliptical defect as a function of traffic accumulation.

\section{STRESS INTENSITY FACTOR CALCULATIONS}

Stress intensity factor is a fracture mechanics parameter that characterizes the intensity of stress concentration ahead of a crack. The stress intensity factors developed in this paper are based on simplifying assumptions. For example, the rail is assumed to behave as a beam in pure bending. That is, bending occurs from a vertical wheel load applied at the vertical centerline of the rail. Eccentric vertical loads, lateral loads, and longitudinal rail force due to thermal expansion/contraction are neglected. Moreover, the defect is idealized as a semi-elliptical crack centered on the rail base (Figure 4). The semi-elliptical crack is characterized by depth or size, $a$, and aspect ratio, $b / a$. Calculations are conducted for different sizes and aspect ratios.

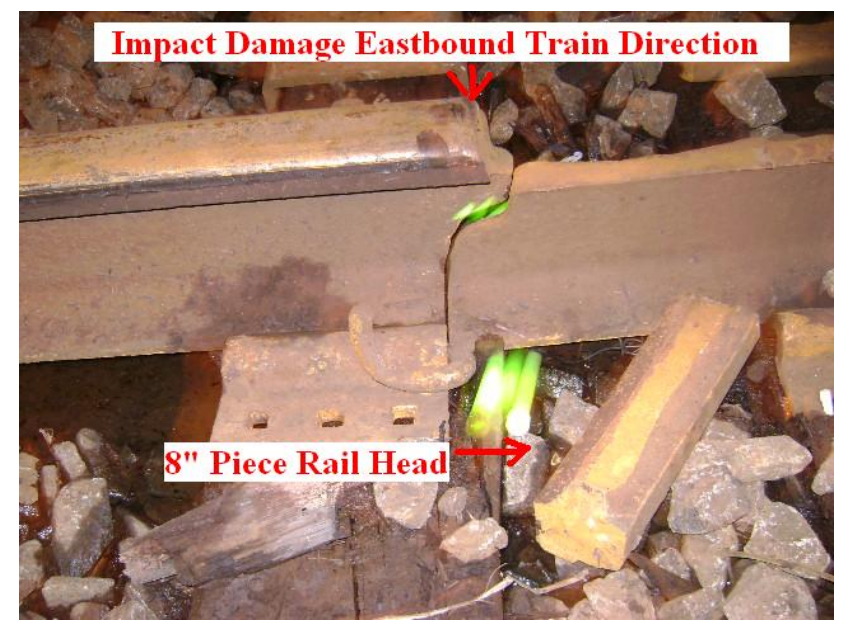

Figure 1: Broken Rail Involved in Recent Derailment

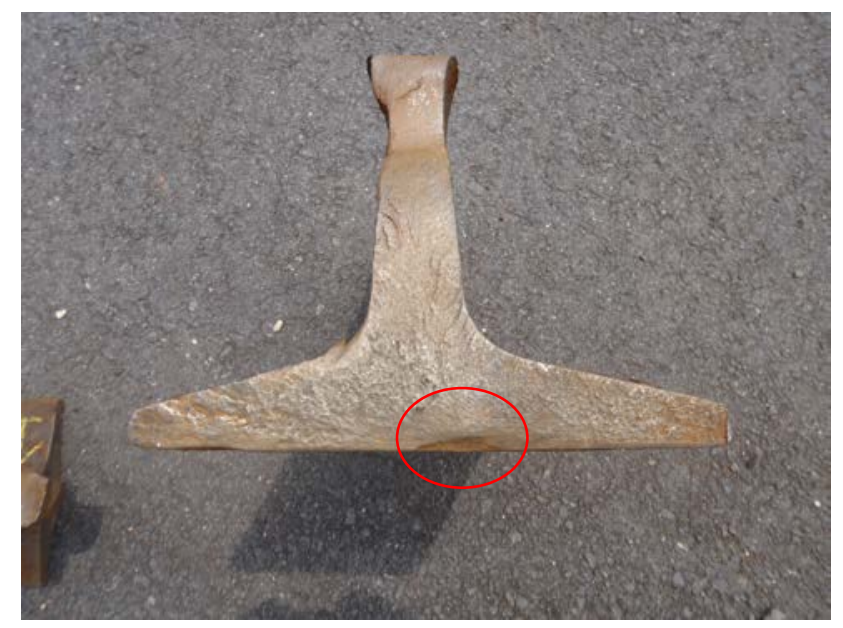

Figure 2: Crescent-shaped Crack Radiating from Corrosion Pit

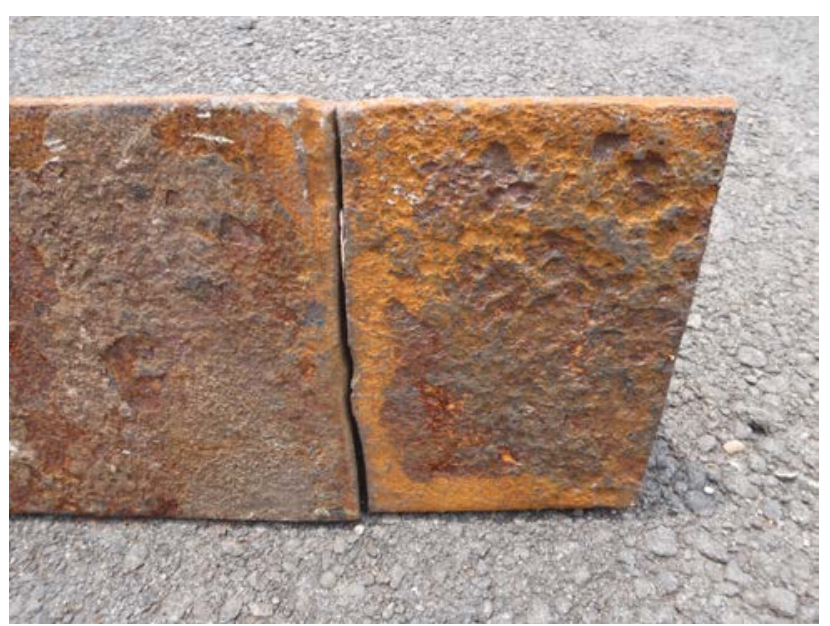

Figure 3: Rust on Underside of the Rail Base 


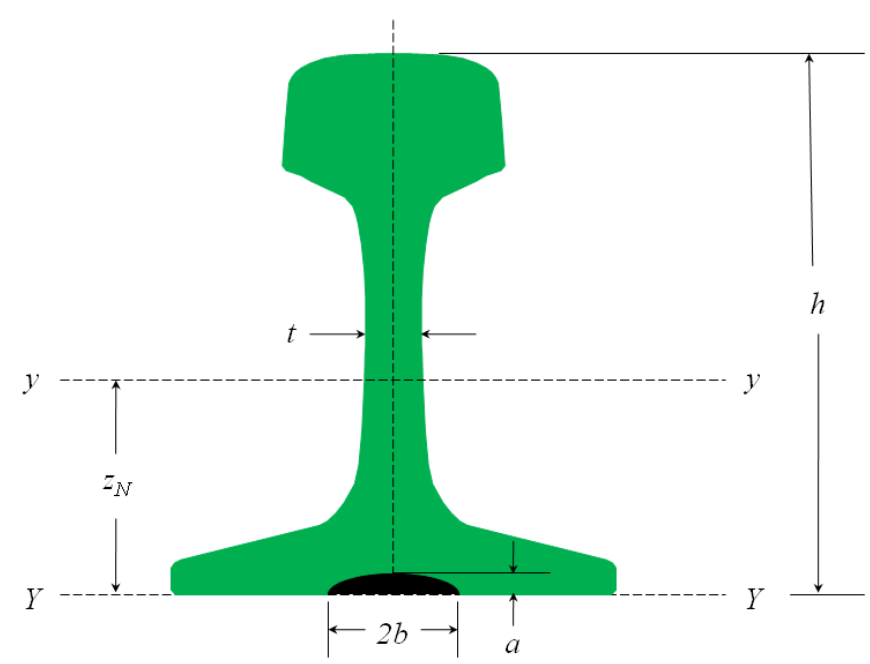

Figure 4: Schematic of Rail Cross Section with Idealized Internal Base Crack

\section{Strength of Materials Considerations}

Table 1 lists dimensions and section properties for an undamaged 140RE rail. However, the section properties change for a rail containing a semi-elliptical crack in the rail base. As the crack becomes larger, the rail cross-sectional area decreases along with a corresponding shift in the neutral axis and reduction in the area moment of inertia. Strength-of-materials considerations are applied to calculate these changes in section properties. Figure 4 is used for reference in developing the following equations.

Table 1: Properties for Undamaged 140RE Rail

\begin{tabular}{lc}
\hline Property & Value \\
\hline Rail height, $h$ & 7.3125 inches \\
Web thickness, $t$ & 0.75 inch \\
Rail centroid relative to rail base, $z_{N}$ & 3.37 inches \\
Cross-sectional area of entire rail, $A_{R}$ & $13.8 \mathrm{in}^{2}$ \\
Cross-sectional area of rail base only, $A_{B}$ & $4.86 \mathrm{in}^{2}$ \\
Moment of inertia, $I_{y y}$ & $96.8 \mathrm{in}^{4}$ \\
\hline
\end{tabular}

For an undamaged rail, the area moment of inertia about a horizontal axis through the rail base is

$I_{Y Y}=I_{y y}+A_{R} z_{N}^{2}$

where $I_{y y}$ is the area moment of inertia about a horizontal axis through the centroid of the entire rail, $A_{R}$ is the cross-sectional area of a new or undamaged rail, and $z_{N}$ is the distance from the rail base to the centroid of the entire rail. The area of a semielliptical crack is
$A_{\text {crack }}=\pi a b / 2$

Therefore, the cross-sectional area of a rail containing a semielliptical crack is

$A_{R}(a)=A_{R}-\pi b a / 2$

For a semi-elliptical crack, its area moment of inertia about a horizontal axis through the rail base is

$I_{\text {YYrack }}=\pi b a^{3} / 8$

For a rail containing a semi-elliptical base crack, its area moment of inertia about a horizontal axis through the rail centroid is

$I_{y y}(a)=I_{Y Y}-I_{\text {YYcrack }}-A_{R}(a) Z_{N}(a)^{2}$

where

$Z_{N}(a)=\frac{A_{R} Z_{N}-2 b a^{2} / 3}{A_{R}-\pi b a / 2}$

Figure 5 shows the location of the centroid of the entire rail relative to the rail base for a 140RE section containing different sizes of semi-elliptical cracks and different aspect ratios. Correspondingly Figure 6 shows the reduction in crosssectional area, and Figure 7 shows the reduction in area moment of inertia for a 140RE section containing different configurations of semi-elliptical cracks.

Following the work in Reference [3], the variation in the area moment of inertia of rail with different crack sizes, $I_{y y}(a)$, can be applied to estimate stress intensity factors for cracked rails under pure bending:

$K_{I}=M \sqrt{\frac{\beta}{t}\left[\frac{1}{I_{y y}(a)}-\frac{1}{I_{y y}}\right]}$

where $M$ is the applied bending moment, $t$ is the web thickness, and $\beta$ is referred to as the magnification factor. In Reference [4], finite element analysis was employed to derive the following magnification factor for cracked I-beams:

$\beta=1.16\left(\frac{a}{h}\right)^{-0.374}$ 


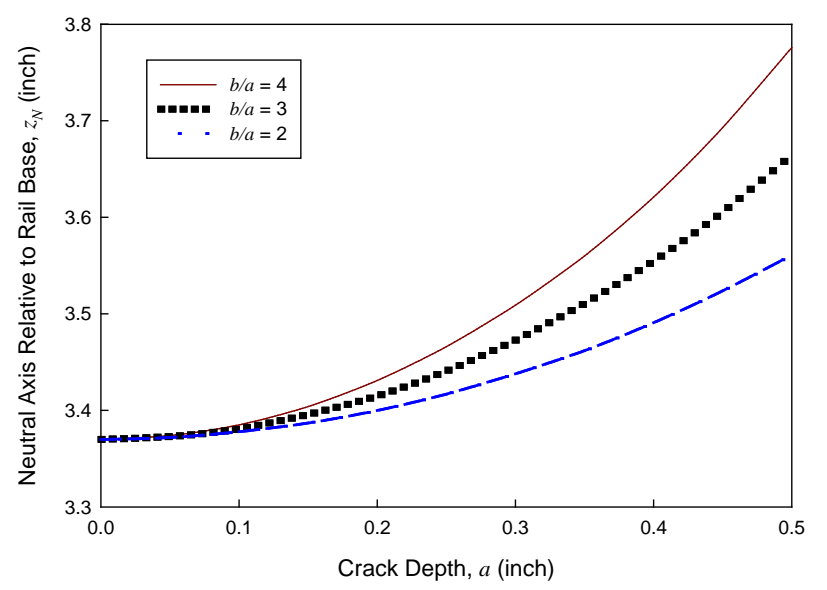

Figure 5: Location of Neutral Axis for Different Semielliptical Rail Base Cracks in 140RE

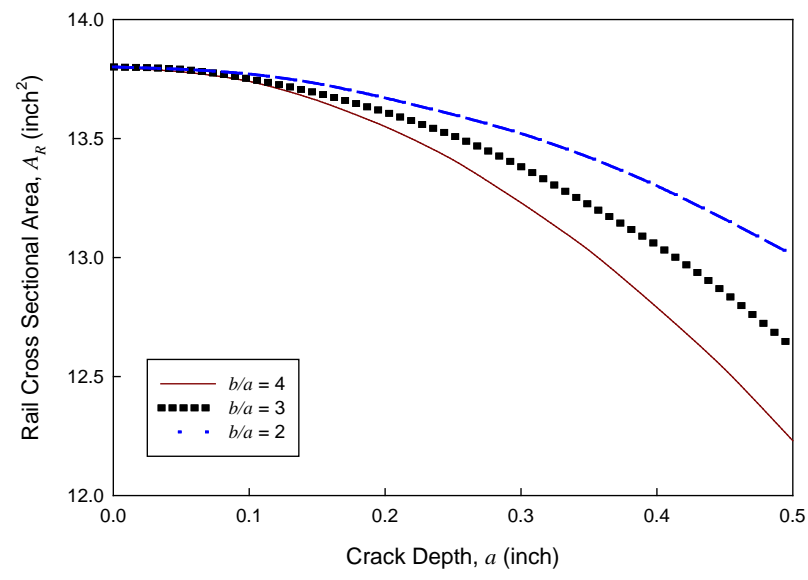

Figure 6: Rail Cross Sectional Area for Different Semielliptical Rail Base Cracks in 140RE

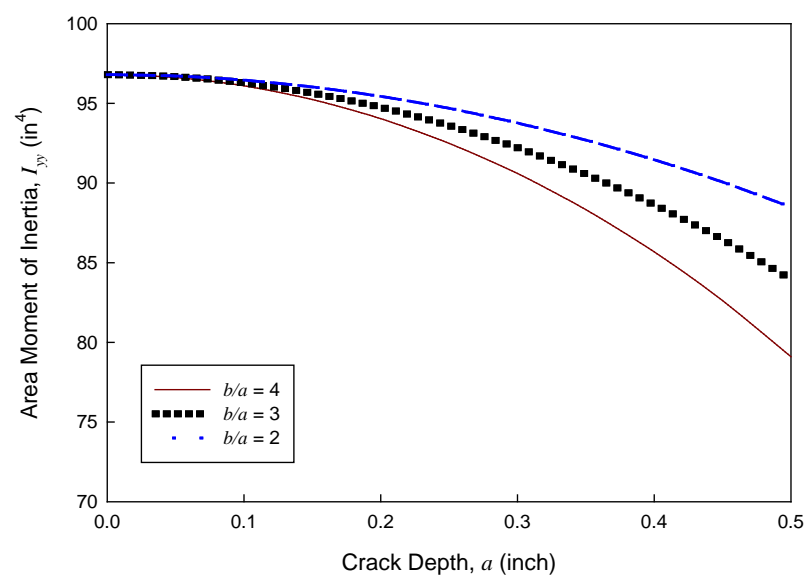

Figure 7: Area Moment of Inertia for Different Semielliptical Rail Base Cracks in 140RE

\section{Estimation by Finite Element Analysis}

ABAQUS/Standard [5] is used to model the rail as a simply-supported beam in four-point bending. The finite element mesh is constructed using 20 -node brick elements. The simplifying assumptions allow for the use of a $1 / 4$-symmetry model. Figure 8 shows the finite element mesh for a 140RE rail containing a semi-elliptical crack in the rail base. The mid-side nodes in the brick elements adjacent to the crack border are shifted to the one-quarter position in order to create the stress singularity to model the crack in the fracture mechanics calculations [6].

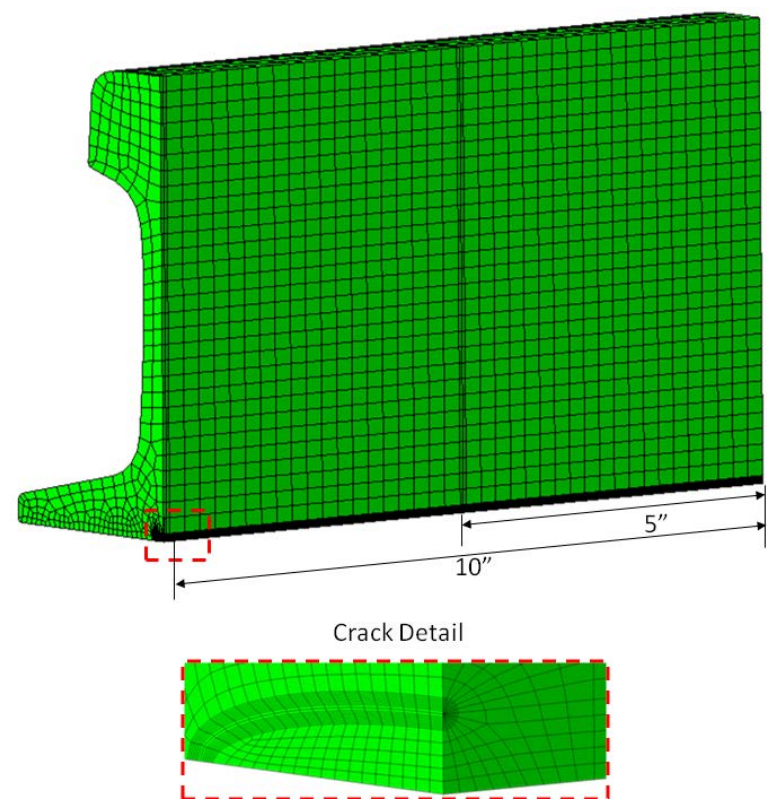

Figure 8: Finite Element Mesh for 140RE with Base Crack

Although the finite element model is three-dimensional, the semi-elliptical crack is assumed to remain planar as it enlarges. Referring to Figure 9, the co-ordinates corresponding to the location of the crack border (also referred to as the crack front) are calculated using the following parametric equations

$Y=b \cos \phi$

$Z=a \sin \phi$

where $b$ is the semi-major length of the ellipse, $a$ is the semiminor length of the ellipse, and $\phi$ is the parametric angle. Moreover, the stress intensity factor for the semi-elliptical crack varies with $\phi$. The maximum value of the stress intensity factor for a given crack is expected to occur at $\phi$ equal to $90^{\circ}$. 


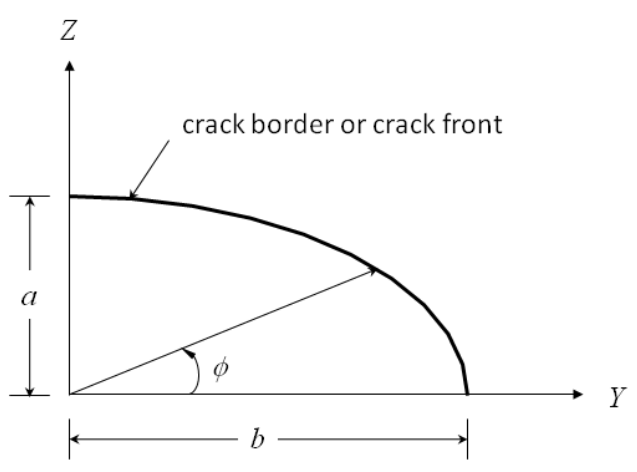

Figure 9: Crack Co-ordinates

In ABAQUS, stress intensity factors are calculated using another fracture mechanics parameter called the $J$-integral. In a linear elastic body containing a crack, the $J$-integral is equal to the strain energy release rate. Under conditions of plane strain, the $J$-integral is related to the stress intensity factor by:

$J=\left(1-v^{2}\right) \frac{K_{I}^{2}}{E}$

where $E$ is the modulus of elasticity (typically $30 \times 10^{6}$ psi for rail steel) and $v$ is Poisson's ratio ( 0.3 for rail steel).

In theory, the $J$-integral is a path independent contour integral [7]. In practice, ABAQUS provides evaluation of the $J$ integral on as many contours as the user requests. The first contour is the ring of elements immediately adjacent to the crack front, and subsequent contours are generated moving away from the crack border. Since the $J$-integral should be path independent, the variation of $J$ among the contours can be interpreted as an indicator of mesh quality.

Results from the finite element analysis are presented in the Appendix for nine different crack configurations: $a=0.1,0.3$, and 0.5 inch and aspect ratios, $b / a=2,3$ and 4 . Results for each crack configuration are presented in terms of normalized stress intensity factor as a function of the parametric angle $\phi$. Normalized stress intensity factor is defined as:

$K_{I}^{*}=\frac{K_{I} t h^{3 / 2}}{M}$

where $t$ and $h$ for 140RE rail are listed in Table 1. The results presented in the Appendix indicate that the maximum stress intensity factor for a given crack configuration occurs at $\phi$ equal to $90^{\circ}$ for nearly all cases considered.

In addition, finite element results for each crack configuration are shown for six (6) contours around the semielliptical crack. In each case, the results from Contours 2 through 6 are nearly identical, whereas the results from Contour 1 tend to oscillate. According to the ABAQUS Benchmarks
Manual, the calculations from the first contour can be ignored because of numerical inaccuracies in the stresses and strains at the crack front. Moreover, the consistency of results from all but the first contour suggests that the finite element mesh is acceptable for the task at hand.

Equation (7) represents a convenient mathematical form of the stress intensity factor to facilitate calculations of crack growth rate, which are described in the next section of this paper. Results from the finite element analysis for $K_{I}$ at an angle of $\phi$ equal to $90^{\circ}$ can be compared to this closed-form equation. However, when equation (8) is used as the magnification factor in equation (7), the resulting closed-form calculations overestimate the stress intensity factors determined by the finite element analysis. In Reference [4], the analysis for cracked I-beams considered cracks that had broken through the entire bottom fillet and part of the web, so that cracking covered a significant portion of the cross-sectional area. In contrast, the largest semi-elliptical crack considered in the present work occupies less than 12 percent of the rail cross-sectional area.

Consequently, the finite element results for $K_{I}$ at $\phi$ equal to $90^{\circ}$ are used to perform a curve-fit regression analysis and derive a magnification factor that is specific to the $140 \mathrm{RE}$ rail section:

$\beta=0.112\left(\frac{b}{a}\right)^{-0.562}\left(\frac{a}{h}\right)^{-1.054}$

Figure 10 shows the normalized stress intensity factor calculated using equation (7) with equation (13) as the magnification factor. For comparison, the figure also includes the results from the finite element analysis for $K_{I}$ at $\phi$ equal to $90^{\circ}$. The figure indicates that the regression analysis for the magnification factor provides a reasonable fit to the finite element calculations.

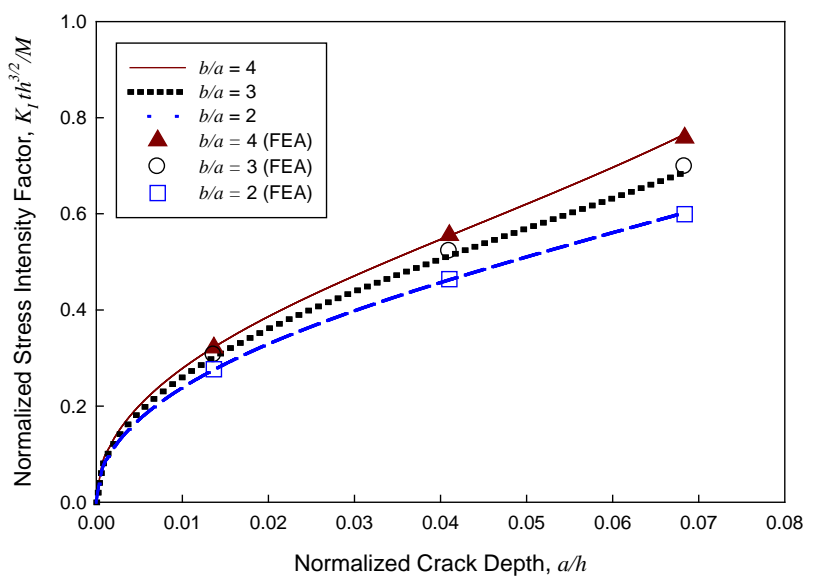

Figure 10: Stress Intensity Factor as a Function of Crack Depth 


\section{DEFECT GROWTH CALCULATIONS}

Estimates for crack growth are calculated using the following equation [7]:

$$
\frac{d a}{d N}=C \frac{\Delta K_{I}^{p}}{(1-R)^{q}}
$$

where $a$ is the crack depth, $N$ is the number of cycles, $\Delta K_{I}$ is the stress intensity factor range, and $R$ is the stress ratio (defined as the ratio of minimum stress to maximum stress). In addition, $C$, $p$ and $q$ are empirical constants. This equation was used in previous research to estimate the propagation life of detail fractures in rails [2]. The empirical constants assumed for rail steel are listed in Table 2.

Table 2: Empirical Constants for Growth Rate Equation

\begin{tabular}{ccc}
\hline $\begin{array}{c}C \\
\left.\text { inch-(ksi-in }{ }^{1 / 2}\right)^{-p} \text { cycle }^{-1}\end{array}$ & $p$ & $q$ \\
\hline $1 \times 10^{-11}$ & 4 & 1.63 \\
\hline
\end{tabular}

Equation (14) is treated as a separable differential equation to calculate the number of cycles to grow a crack from an initial depth, $a_{i}$ to a larger depth:

$N=\frac{1}{C(1-R)^{q}} \int_{a_{i}}^{a_{i}+\Delta a} \frac{d a}{\Delta K_{I}(a)^{p}}$

where $\Delta a$ is the increment of growth. In applying this equation, the growth of the crack is assumed to be self-similar. In this context, self-similar means that the aspect ratio of the semielliptical crack is assumed to remain constant as the crack enlarges. The number of cycles, $N$ is converted into traffic accumulation or tonnage in terms of million gross tons (MGT) by multiplying cycles by axle load (in tons).

Crack growth is assumed to occur from constant-amplitude stress cycles created by rail bending from the repetition of vertical wheel loads. Furthermore the stress ratio, $R$ is assumed to be equal to zero. The physical interpretation of this stress ratio is that the entire stress cycle is tensile. Under this loading condition, $\Delta K_{I}$ is equal to $K_{I}$, where $K_{I}$ corresponds to the stress intensity factor at the maximum bending moment.

The flexural behavior of a rail in track under a passing wheel load can be accurately calculated using an analysis of the rail as a uniform beam supported by a continuous, linear and elastic foundation. From Hetenyi [9], the maximum bending moment created by an applied load, $P$ is

$M=\frac{P}{4 \lambda}$
In this equation, $\lambda$ is a wavelength parameter defined as

$\lambda=\sqrt[4]{\frac{k}{4 E I_{y y}}}$

where $k$ is the foundation modulus, $E$ is the modulus of elasticity for rail steel, and $I_{y y}$ is the area moment of inertia for the undamaged rail.

Table 3 lists the different load cases for crack growth estimates considered in this paper. The 19-kip wheel load represents the static wheel load for a passenger car. The foundation modulus of 10,000 psi corresponds to the ballast support offered by concrete ties. The variations in wheel load and foundation modulus are intended to show the relative effects of heavier cars and degraded ballast support on the estimated crack growth rate.

Table 3: Crack Growth Load Cases

\begin{tabular}{cccc}
\hline Case & $\begin{array}{c}\text { Wheel } \\
\text { Load, } P \\
(\mathrm{lb})\end{array}$ & $\begin{array}{c}\text { Foundation } \\
\text { Modulus, } k \\
(\mathrm{psi})\end{array}$ & $\begin{array}{c}\text { Bending } \\
\text { Moment, } M \\
\left(10^{3} \text { inch-lb }\right)\end{array}$ \\
\hline 1 & 19,000 & 10,000 & 155.9 \\
2 & 33,000 & 10,000 & 270.8 \\
3 & 19,000 & 1,000 & 277.3 \\
\hline
\end{tabular}

In previous work on rail head defects called detail fractures, crack size is characterized in terms of percent rail head area. Similarly the size of the semi-elliptical rail base crack can be expressed in terms of its area relative to the rail base area, which is equal to $4.86 \mathrm{in}^{2}$ for 140RE rail (Table 1). That is, growth is calculated in terms of crack size in percent rail base area (\%BA). Equation (2) is used to calculate the area of the semi-ellipse. The chain rule of calculus is then applied to equation (15) to affect the change in variable from crack depth (in units of length) to crack size (in units of area).

The initial crack size, $a_{i}$ is assumed to be $10 \% \mathrm{BA}$, which roughly corresponds to the smallest defect size that nondestructive testing equipment can detect. The crack growth calculations in this paper terminate at a crack size of $50 \% \mathrm{BA}$. Cracks covering slightly more than half the rail base area begin to enter into the rail web (Figure 11). Once the crack propagates into the web, its shape deviates from a semi-ellipse, and the assumption of self-similar crack growth no longer applies.

Figure 12 shows estimates for the growth of semi-elliptical cracks with different aspect ratios for Load Case 1 . The figure indicates that cracks with larger aspect ratios tend to grow faster. The fatigue life for cracks with aspect ratio equal to four (257 MGT) is about two-thirds of that for cracks with $b / a$ equal to two (381 MGT). In this context, fatigue life refers to the tonnage to grow a crack from 10 to $50 \% \mathrm{BA}$. 


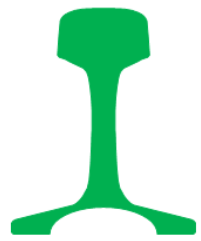

$b / a=2$

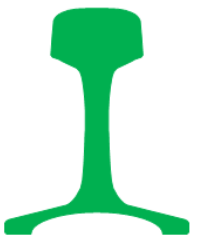

$b / a=3$

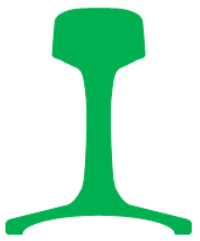

$b / a=4$
Figure 11: Semi-elliptical Rail Base Cracks Covering 50\% of Rail Base Area in 140RE

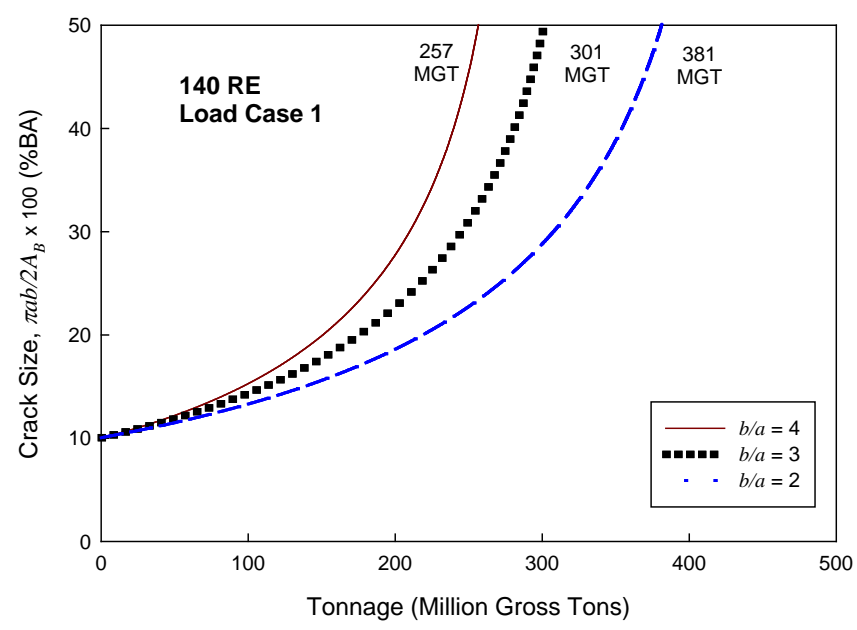

Figure 12: Estimated Growth Curves for Different Aspect Ratios (Load Case 1)

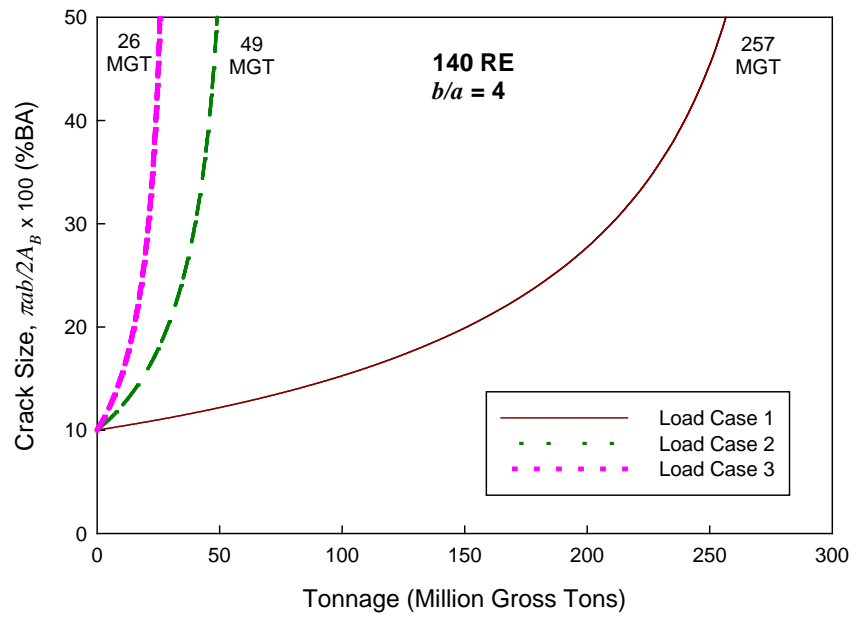

Figure 13: Estimated Growth Curves for Different Load Cases $(b / a=4)$
Figure 13 shows results for the crack growth under the three different load cases listed in Table 3. In these results, the aspect ratio of the semi-elliptical crack, $b / a$, is constant and equal to four. These results indicate that the applied bending moment has a significant effect on the growth rate. Moreover, freight-type wheel loads can reduce the fatigue life by a factor of five, whereas poor foundation support can reduce fatigue life by a factor of ten. Note that the scale on the horizontal axis for tonnage in Figure 13 is compressed, compared to the scale in Figure 12.

\section{DISCUSSION}

The motivation for estimating crack growth rates is to provide guidance in scheduling rail tests in order to detect fatigue cracks before they become large enough to cause a rail failure. The interval between rail tests should not be greater than the tonnage to grow a crack from barely detectable size to the size at which rail failure is expected (i.e. critical size). Such an interval would allow at least one opportunity to detect a crack or defect before it reaches its critical size.

However, the reliability of detecting cracks in the rail base may not be well established since the primary focus of rail testing is usually given to finding internal defects in the rail head because such defects are the primary cause of rail failures. Finding corrosion damage in the rail base is even more problematic. The most reliable method to detect corrosion damage is visual inspection, but the corrosion damage described here is on the underside of the rail where it cannot be seen visually.

By definition, corrosion is deterioration of material due to its interaction with its environment. Corrosion is assumed to be a contributing factor in the initiation and growth of fatigue cracks in the rail base. The effect of corrosion on fatigue crack growth has two separate aspects. One aspect is fatigue crack growth in a corrosive environment. The rail may be submerged in water during stress cycling. In this case, water between the crack surfaces keeps the crack open and accelerates the growth rate. The other aspect is metal fatigue of corroded material. In this case, the rail may be dry but corrosion has degraded the mechanical properties of the rail which also accelerates the growth rate. Neither aspect has been considered in this paper.

Corrosion has an interacting role with fatigue cracking in terms of rail renewal. In this regard, fatigue cracking and corrosion damage may be viewed as competing failure modes that limit the effective life of rail. Remedial actions such as rail replacement must be taken whenever certain defects are found. Recently, guidelines on rail corrosion have been developed under the Transit Cooperative Research Program [10]. These guidelines recommend that the rail should be condemned when the maximum corrosion-induced depth from the bottom of the rail reaches $1 / 2$ inch. However, current rail test technologies are unable to detect these types of defects reliably. 
The growth estimates presented here are based on loading conditions that consider only bending from vertical loads. Inclusion of lateral loads would amplify the total bending stress which would accelerate the crack growth rate. Longitudinal rail force is not included in these estimates because it is assumed that thermal expansion of the rails is not likely to occur in tunnels.

While the strength-of-materials considerations can be generalized to consider other rail sections, the finite element analysis (FEA) and the magnification factor developed from the FEA results are specific to a 140RE rail section. In order to examine the effect of rail section on crack growth rate, it would be necessary to generate finite element meshes for those rail sections of interest. The procedure described in this paper could then be repeated to develop stress intensity factors that would be specific to those rail sections.

The semi-elliptical rail base defect is modeled as planar (i.e. two-dimensional) crack. In addition, the growth of this crack is assumed to be self-similar (i.e. the semi-elliptical shape remains constant as the crack enlarges). The photograph in Figure 1 shows that, in the rail that caused the derailment, the crack propagated from the rail base up through the web and turned longitudinally as it grew toward the rail head. With this turning of the crack, the entire crack becomes three-dimensional and its growth becomes non-self-similar. Progression of a three-dimensional (3-D) crack could be predicted using advanced finite element analysis techniques. In such an analysis, it would be necessary to (1) determine stress intensity factors for three modes corresponding to opening, sliding, and tearing stresses, and (2) assume an appropriate criterion to determine how the crack will turn under mixed mode loading. In this paper, only the opening mode stress intensity factor due to pure bending has been considered. In a 3-D analysis, residual stresses could play a significant role in predicting the trajectory of the crack. Limited data exist for measurements of residual stresses in rails. In the present work, residual stresses are neglected.

No experimental data are currently available to confirm the calculations of crack growth rate. The actual growth rate of semi-elliptical rail base cracks is expected to be faster than the estimated growth rates due to the simplifying assumptions in the calculations.

Previous FRA-sponsored research on defect growth has focused on detail fractures, which propagate in the rail head. The estimated growth rate of semi-elliptical cracks in the rail base is slower than the established growth rates for detail fractures. This result is consistent with practical experience, where broken rails are more likely to occur from defects or cracks in the rail head rather than the base.

The constants assumed in the growth rate equation, which are listed in Table 2, are based on laboratory tests using specimens machined from the rail head. However, microstructure differences in the head and in the base of the rail might have an influence on crack growth. Conducting laboratory fatigue crack-growth tests using specimens machined from the rail base would be useful to examine the effect of the microstructural differences on crack growth.

\section{CONCLUDING REMARKS}

In this paper, strength-of-materials considerations are combined with finite element analysis to estimate stress intensity factors for semi-elliptical cracks in the base of a 140RE rail. The stress intensity factors are then used to estimate crack growth rates, which may be used to help schedule periodic rail inspections to detect cracks before they grow large enough to cause a rail failure.

The crack growth rate estimates indicate relatively slow growth under loading conditions corresponding to passenger cars travelling over track supported by concrete ties. However, the rate of crack growth accelerates rapidly as wheel loads increase and as ballast support deteriorates. Moreover, the results in this paper suggest that heavy wheel loads can reduce the tonnage to grow a semi-elliptical base defect from 10 to $50 \% \mathrm{BA}$ by a factor of five. Under poor foundation conditions, the estimated fatigue life reduction is a factor of ten.

\section{NOMENCLATURE}

$A_{B} \quad$ Cross-sectional area of rail base only

$A_{R} \quad$ Cross-sectional area of entire rail

a Semi-minor axis length of semi-elliptical defect

$a_{i} \quad$ Initial crack depth

$b \quad$ Semi-major axis length of semi-elliptical defect

C Constant in crack growth rate equation

E Modulus of elasticity

$h \quad$ Height of rail

$I_{y y} \quad$ Vertical bending inertia of rail about its centroid

$J \quad J$-integral

$K_{I} \quad$ Mode I stress intensity factor

$k \quad$ Foundation modulus

$M \quad$ Bending moment

$N \quad$ Number of cycles

$P \quad$ Wheel load

$p \quad$ Exponent in crack growth rate equation

$q \quad$ Exponent in crack growth rate equation

$R \quad$ Stress ratio

$t \quad$ Thickness of rail web

$z_{N} \quad$ Location of neutral axis relative to rail base

$\beta \quad$ Magnification factor

$\Delta a \quad$ Incremental crack growth

$\phi \quad$ Parametric angle to define crack border

$\lambda \quad$ Wavelength parameter

$v \quad$ Poisson's ratio

\%BA Percent rail base area

\section{ACKNOWLEDGMENTS}

The work described in this paper was sponsored by the Federal Railroad Administration, Office of Research and Development. Mr. Gary Carr is the Chief of the Track Research 
Division. Mr. Ali Tajaddini is the Program Manager for the research related to rail integrity. Technical discussions with Dr. Oscar Orringer, our colleague at the Volpe Center, are greatly appreciated.

\section{REFERENCES}

[1] Jeong, D.Y., "Progress in Rail Integrity,” Final Report, DOT/FRA/ORD-01/18, October 2001.

[2] Orringer, O., Y.H. Tang, J.E. Gordon, D.Y. Jeong, J.M Morris and A.B. Perlman, "Crack Propagation Life of Detail Fractures in Rails,” Final Report, DOT/FRA/ORD88/13, October 1988.

[3] Gao, H. and G. Herrmann, "On estimates of stress intensity factors for cracked beams and pipes,” Engineering Fracture Mechanics 41, 1992, pp. 695-706.

[4] Dunn, M.L., W. Suwito, and B. Hunter, "Stress intensity factors for cracked I-beams," Engineering Fracture Mechanics 57, 1997, pp. 609-615.

[5] ABAQUS/Standard 6.10, Dassault Systèmes Simulia Corp., Providence, RI, 2010.

[6] Henshell, R.D. and K.G. Shaw, "Crack tip finite elements are unnecessary," International Journal for Numerical Methods in Enginering 9, 1975, pp. 495-507.

[7] Rice, J.R., "A path independent integral and the approximate analysis of strain concentration by notches and cracks," Journal of Applied Mechanics 35, 1968, pp. 379-386.

[8] Walker, K. “The effect of stress ratio during crack propagation and fatigue for 2024-T3 and 7075-T6 aluminum," Effects of Environment and Complex Load History on Fatigue Life, ASTM STP 462, American Society for Testing and Materials, 1970, pp. 1-14.

[9] Hetenyi, H., Beams on Elastic Foundation, University of Michigan Press, Ann Arbor, MI, 1974.

[10] Aktar, M., “Guidelines for Rail Base Inspection and Rail Condemnation Limits for Corrosion Induced Material Loss,” Transit Cooperative Research Program Project D7/Task 17, Transportation Research Board, Washington, DC, March 2009.

\section{APPENDIX - FINITE ELEMENT RESULTS}

This appendix presents the results from the finite element analysis to calculate stress intensity factors along the crack border for nine crack configurations in 140RE rail. These configurations are defined by crack size or depth, $a$, and aspect ratio, $b / a$. In each figure, the normalized stress intensity factor is plotted as a function of the parametric angle, $\phi$, which defines the crack border (see Figure 9). Each plot shows results from six contours that represent increasingly larger areas surrounding the crack, where the first contour is closest to the crack border. The scale for the normalized stress intensity factor varies depending on the crack size since the stress intensity factor increases with increasing crack size.

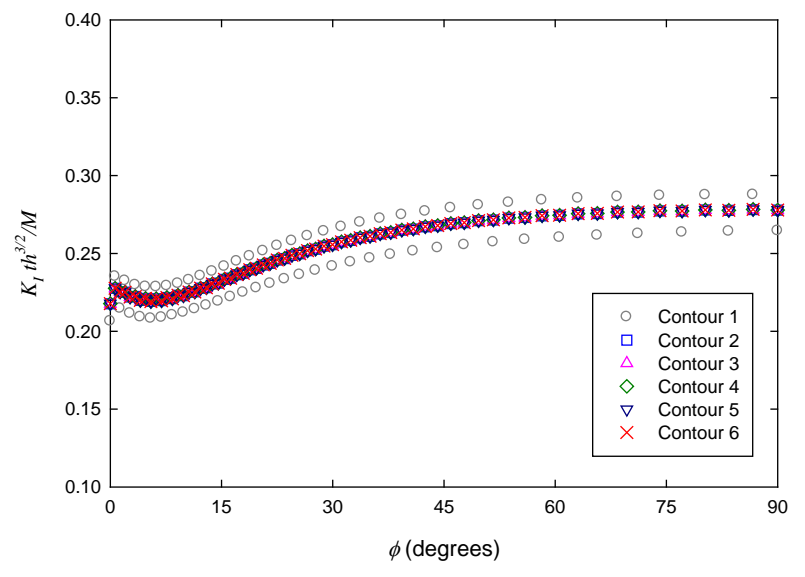

Figure 14: FEA Results for $a=0.1$ inch, $b=0.2$ inch

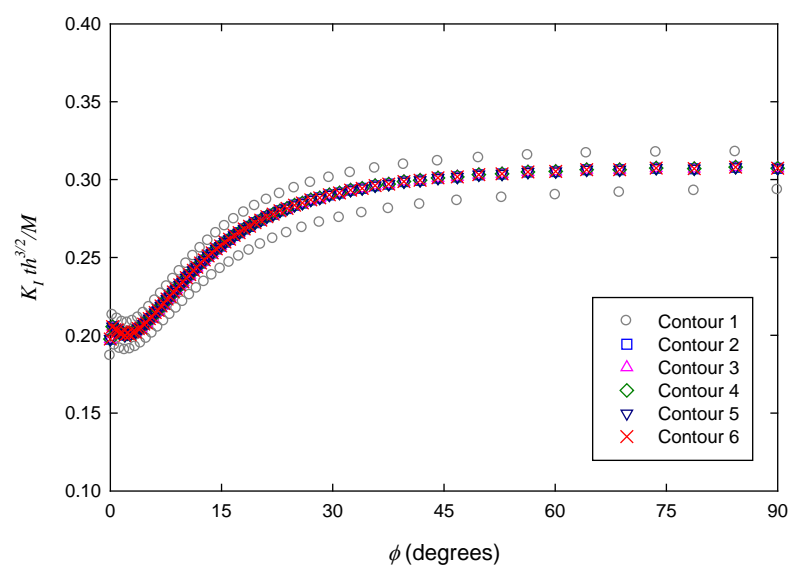

Figure 15: FEA Results for $a=0.1$ inch, $b=0.3$ inch

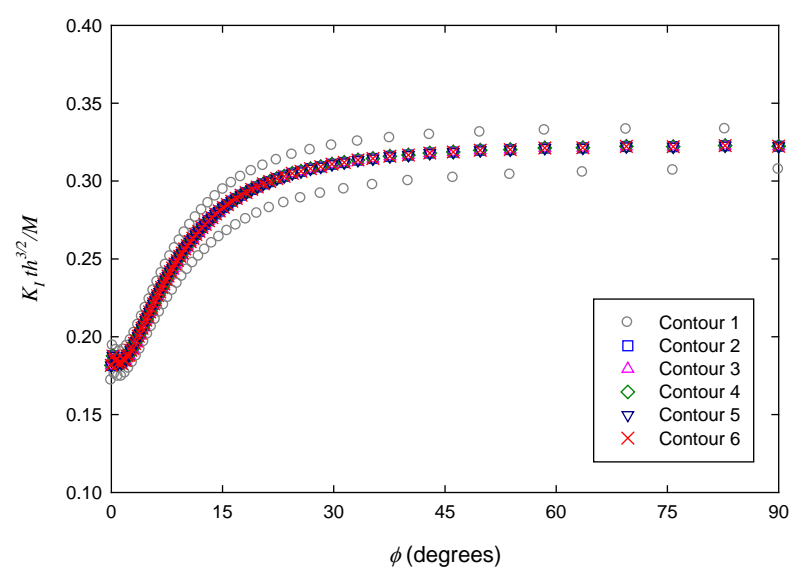

Figure 16: FEA Results for $a=0.1$ inch, $b=0.4$ inch 


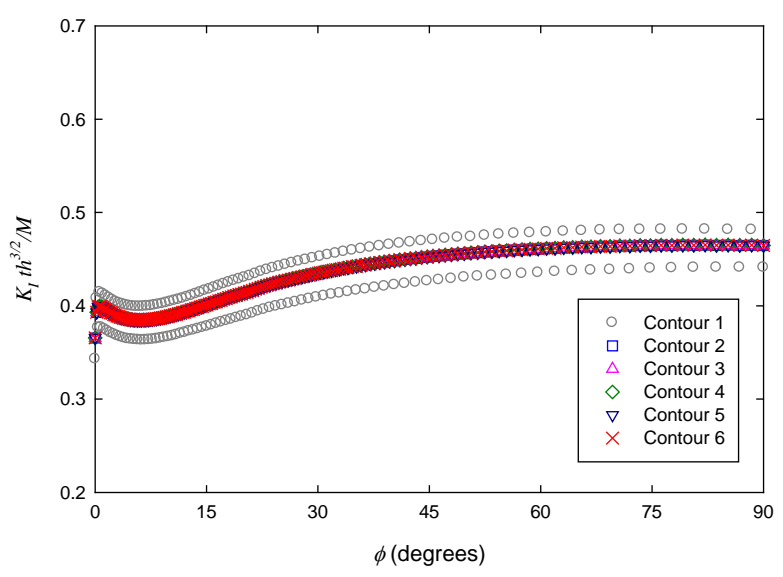

Figure 17: FEA Results for $a=0.3$ inch, $b=0.6$ inch

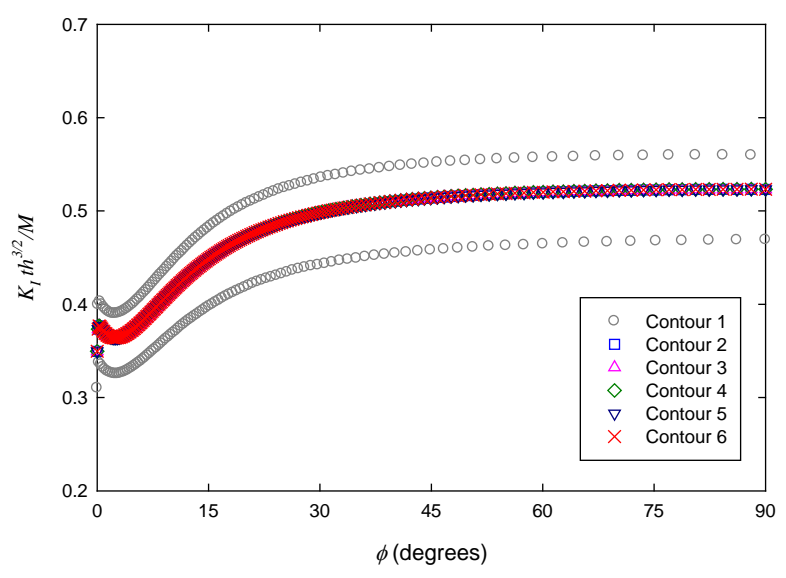

Figure 18: FEA Results for $a=0.3$ inch, $b=0.9$ inch

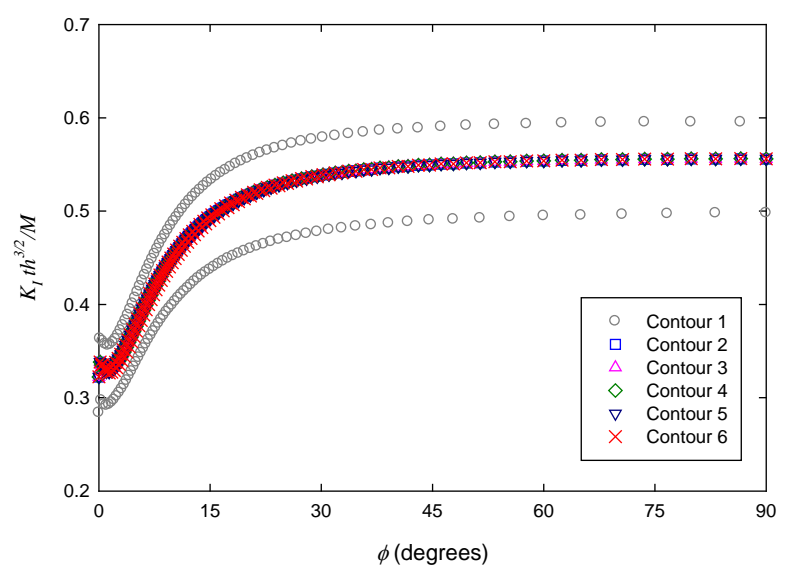

Figure 19: FEA Results for $a=0.3$ inch, $b=1.2$ inches

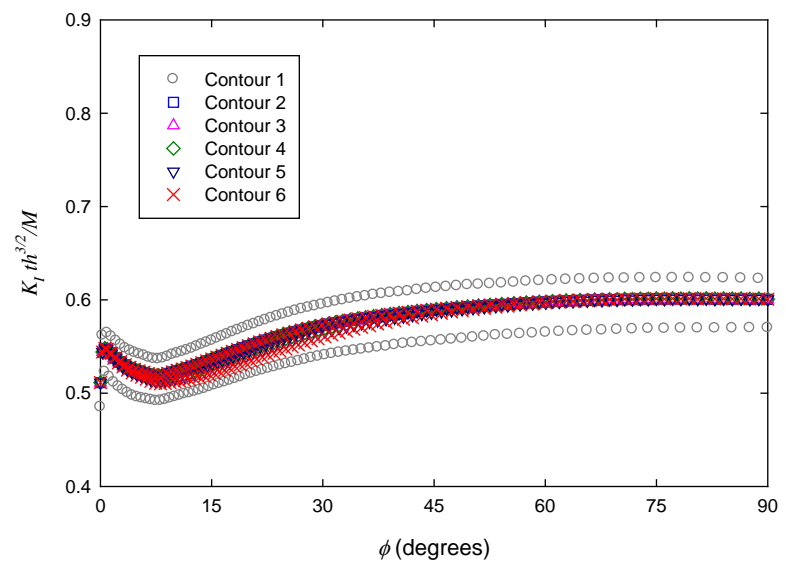

Figure 20: FEA Results for $a=0.5$ inch, $b=1.0$ inch

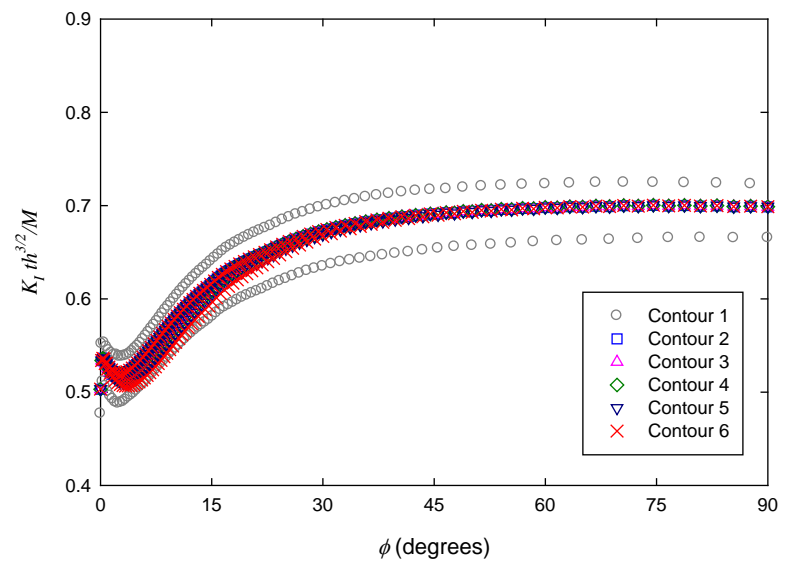

Figure 21: FEA Results for $a=0.5$ inch, $b=1.5$ inches

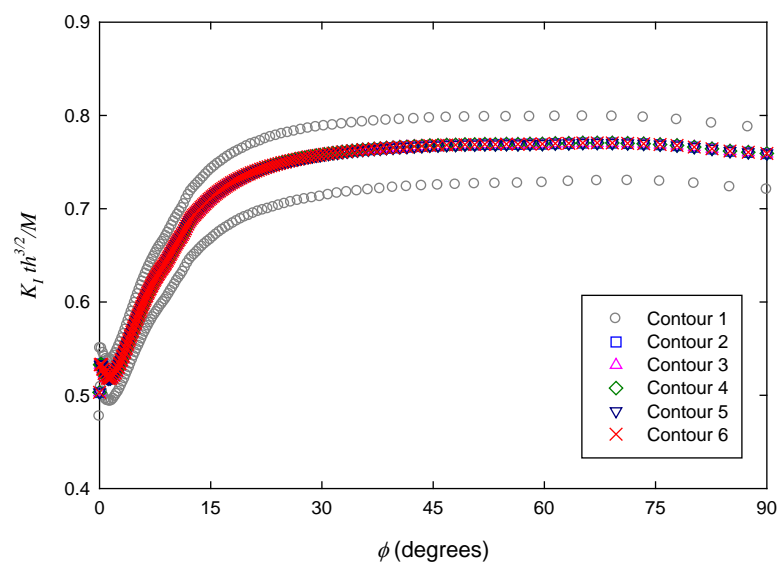

Figure 22: FEA Results for $a=0.5$ inch, $b=2.0$ inches 